\title{
Hidra System(!) in the tension between Internet of Things and Virtual Reality: programming meta-objects
}

\section{SIGRADI2018 TECHNOPOLITICAS \\ xxii congresso da sociedade iberoamericana de gráfica digital 22th conference of the iberoamerican society of digital graphics 07|08|09|novembro|2018 iau usp | são carlos | sp br}

\author{
Prof. Dr. Sandro Canavezzi de Abreu \\ Escola de Arquitetura - UFMG | Brazil | sandroid@gmail.com
}

\begin{abstract}
We will characterize the relationship between Internet of Things (IOT) and Virtual Reality (VR) as the tension between analog and digital domains, organized by several interfaces specifically developed for this study, during de course Interactive Architecture at the Architecture School - UFMG. These interfaces, referred here as programmable meta-objects (MOPs), recombine themselves to form an environment where inputs and outputs of each MOP are made available to other networked MOPs through the Hydra System (!). These MOPs can have both a physical existence (object present in physical space) and a "virtual" existence (it exists in the Virtual Reality environment).
\end{abstract}

Keywords: Hidra System(!); Virtual Reality; Internet of Things; Combinatorial; Meta-objects; Programmable.

\section{INTRODUÇÃO}

Com a inserção cada vez mais pronunciada de objetos que são capazes de se conectar à internet (conhecida como Internet das Coisas - IOT) e assim possibilitar a captação de informações sobre o ambiente onde estão inseridos e, principalmente, sobre o comportamento do usuário nesse ambiente (conjugado com seu comportamento na internet), transmitindo essas informações para processos digitais cada vez mais complexos e obscuros situados localmente ou na nuvem, questiona-se 0 quanto 0 usuário se distancia dos momentos de tomadas de decisão presentes nesses processos. Com a inserção de tecnologias relativas à Inteligência Artificial, principalmente aquelas chamadas de aprendizado de máquina, constrói-se uma autonomização crescente da máquina nos processos de decisão. Essa autonomização, muitas vezes disfarçada e vendida como algo positivo pois age como facilitadora em processos que "preferiríamos "que fossem automáticos, retira do usuário um poder decisório que normalmente passa despercebido: o de poder não apenas escolher entre as opções pré-estabelecidas desse sistema mas de, principalmente, poder recriá-los ou redesenhá-los de acordo com seus interesses (e não apenas os interesses projetados pelos designers de interfaces). Resumidamente, vende-se a ideia de que é preferível que o sistema tome decisões pelo usuário pois, devido à complexidade dos processos envolvidos, é vantajoso que o usuário não participe desses processos. Na verdade, no entanto, o que acreditamos que aconteça é que os sistemas são intencionalmente desenhados para serem inacessíveis quanto a possibilidade de serem redesenhados. Nesse artigo apresentaremos estratégias para que esse redesenho seja possível, empoderando o usuário frente às tecnologias digitais. No entanto, como veremos, essa possibilidade de criar/redesenhar também implica na transformação do usuário e não apenas nos processos de redesenho. Essa transformação não é relativa apenas ao incremento de conhecimentos tecnológicos mas, principalmente, à construção de um entendimento possível do sistema como um todo: a natureza e papel dos elementos desse sistema e possibilidades de relações entre esses elementos.

A construção desse entendimento, portanto, passa pela compreensão de certos conceitos que acreditamos poder esclarecer como se dão essas relações e, principalmente, como essas relações podem ser estruturadas para se tornarem passíveis de serem reconfiguradas, redesenhadas ou recriadas.

Devemos, no entanto, entender essa sistematização e rede de conceitos mais como construtos que funcionam como recursos e artifícios que compõem uma estratégia do que como teorizações canonizantes. A intenção é, portanto, estabelecer maneiras de atuar na interação homem/sistemas digitais a partir da sistematização aqui proposta.

Como parte da estratégia, associamos IOT com o a tecnologia de Realidade Virtual. Como veremos, essa opção auxiliou na visibilidade do contraste entre um universo híbrido composto por elementos e processos digitais e físicos (IOT) e um que poderíamos entender como sendo do predomínio do digital, onde um processo exclusivamente digital, o da simulação, está onipresente: a Realidade Virtual (RV).

A relação entre IOT e RV em um primeiro momento será construída, tanto conceitualmente como tecnicamente, como sendo uma relação de tensão: campos/domínios distintos tentando se comunicar. Essa abordagem parte do conceito de Schnittstelle (Zielinski, 1997). Essa tensão acontece pois a comunicação será entendida como resultante da contraposição/diferença: polos opostos tentando se comunicar. Essa distinção será fortalecida 
pela associação do digital com o conceito de informação (Shannon, 1940) e do analógico/físico com o conceito de transdução (Simondon, 1986). A tensão se daria, assim, pela contraposição entre transdução e informação.

Em um segundo momento refinaremos essa a relação entre IOT e RV ao enfatizarmos não a diferença entre digital e analógico mas sim as similaridades e correlações a partir do conceito de MOPs (meta-objetos programáveis). Esses meta-objetos são híbridos entre os domínios analógicos e digitais com a possibilidade de terem inputs, outputs e, principalmente, sua própria programação como sendo não-locais. Além disso, como veremos, um meto-objeto pode ser composto por elementos de objetos físicos e elementos de objetos "virtuais".

Para efetivarmos essas compreensões, desenvolvemos um experimento chamado IOT/RV/MOP-1 na disciplina Arquitetura e Interatividade da Escola Escola de Arquitetura - UFMG, onde pudemos desenhar e redesenhar objetos e instalações interativas tendo a combinatória como artifício de criação. A recombinação entre os elementos do sistema foi propiciada pelo Sistema Hidra(!): uma interface que propicia a recombinação entre inputs e outputs dos elementos do sistema possibilitando ainda que a programação desse objeto não necessariamente tenha que estar situado no objeto: O comportamento do objeto pode ser ditado por uma programação não local. Com isso, podemos dizer que a principal característica do Sistema Hidra(!) é possibilitar o contínuo redesenhar das interfaces envolvidas na interação e no sistema como um todo. Podemos entender, assim, o Sistema Hidra(!) como parte fundamental dos MOPs, pois é pelo Hidra(!) que as camadas dos MOPs se recombinam.

Passaremos agora à definição dos conceitos aqui elencados e posteriormente os associaremos com o experimento citado.

\section{SHINITSTELLE}

Adotamos a abordagem de Siegfried Zielinski onde se estabelece uma dualidade complementar entre duas ações que a interface realiza: a conexão e a separação. A interface, assim, conotaria um campo de tensão (Schnittstelle: o lugar da ruptura, do corte, em alemão) que coordena a conexão e a separação: "A interface é algo que separa (uma coisa da outra). Do contrário, o termo não faria sentido. A interface é algo que conecta (uma coisa com a outra). Do contrário, o termo não faria sentido. A interface denota diferença e conexão." (Zielinski, 1997). A interface conecta, pois nela se constrói a semelhança entre aqueles que buscam se conectar. A interface também separa, pois nela são obliteradas as diferenças entre aqueles que se comunicam. "Aquilo que a interface tanto separa como conecta é, em um sentido mais geral, o 'Um' do 'Outro'” (Zielinski, 1997). Um do Outro: utilizam-se ou criam-se interfaces para a conexão com o desconhecido, com o Outro. Esse Outro pode ter diversas conotações. Nesse artigo nos interessa associar o conceito de Schinitstelle com os pólos IOT e RV, construindo distinções e aproximações.
Retornando a Zielinski, ele estabelece ainda que a conexão se realiza de um modo específico: "Através da interface, os Uns definem suas relações com os Outros, com aqueles que diferem deles (dos Uns), isto é, são essencialmente desconhecidos e vice-versa: através da interface, o Um se manifesta para o Outro, no entanto, apenas nos aspectos que lhe são compreensíveis." (Zielinski, 1997). Nesse item, uma afirmação é de extrema relevância: a conexão acontece a partir do que se conhece, do que é compreensível para ambos os lados da interface. É na interface que se opera uma tradução, uma modelagem. Eu modelo o Outro para me comunicar e me modelo para que possa ser compreensível para o Outro. Conota-se aqui que, embora - Outro seja, em grande parte, desconhecido, ao modelálo eu sou capaz de estabelecer uma conexão que possibilita uma atuação/interferência ou comunicação com esse Outro. Essa conceituação nos mostra, assim, que a interface conecta através da construção da semelhança, pela aproximação do que antes estava separado e simultaneamente, opera uma separação. Nesse sentido, como veremos, o Sistema Hidra(!), em termos técnicos, e o conceito de MOPs, em termos conceituais, são interfaces que organizam a aproximação e a distinção entre IOT e RV.

\section{SISTEMA HIDRA(!)}

O Sistema Hidra(!) (o "!” aqui é uma notação matemática para "fatorial", recurso utilizado em análise combinatória) promove a coordenação e a interação dos aspectos computacionais do ambiente e seus usuários. É importante ressaltar que assumimos o usuário/reprogramador como parte indissociável desse sistema interativo (Pask, 1975). Para que essa interação se efetive, o Sistema Hidra(!) é dividido em três níveis: nível sensório, nível processador e nível atuador.

O nível sensório é formado por objetos técnicos que incorporam diversas formas de sensores de luz, de movimento, de temperatura, de distância, de umidade, de distância, etc. Esses objetos técnicos, aliados a um hardware específico (controladores como Arduinos, Raspberry $\mathrm{Pi}$, LittleBits e similares), convertem sinais analógicos em digitais. É o nível, portanto, onde se realiza a digitalização de sinais analógicos.

O nível processador é a parte que contém a programação, e que é reprogramável. Constitui-se do conjunto de algoritmos que processa as informações digitalizadas de diversas formas, reconhecendo padrões e/ou tomando decisões (via operações booleanas simples ou complexas como I.A. e A.G., por exemplo).

O nível atuador é formado por objetos técnicos que incorporam diversas formas de atuadores. Ele "atua" diretamente no ambiente através de interferências mecânicas (alterações controladas dos movimentos de elementos físicos/materiais desse espaço: abertura/fechamento de portas, janelas, brises, persianas e demais objetos-técnicos e interfaces móveis programáveis) e demais interferências físicas/tangíveis: síntese e manipulação sonora, controle luminoso, controle de temperatura e umidade, síntese e manipulação de imagens, etc. Esse nível é composto por um conjunto de atuadores (LEDs, buzzers, caixas de 
som, projetores, óculos de Realidade Virtual, lâmpadas, relays, servo-motores, motores de passo etc.).

Os níveis são programados utilizando a plataforma MAX7 e a programação foi feita de modo a propiciar a recombinação e o mapeamento dinâmico entre sensores e atuadores, seja localmente ou remotamente (via internet), possibilitando, a título de exemplo, alterar o comportamento de um atuador - como um LED, por ex. - a partir de um sensor de luz situado no mesmo local que o LED ou de um lugar muito distante, no caso, acionado remotamente por um controlador. A utilização dessa plataforma se deu por esta utilizar uma linguagem estruturada em dataflow: os elementos da programação (as funções, variáveis, objetos, etc.) são organizados graficamente e podem ser dinamicamente dispostos e relacionados entre si.

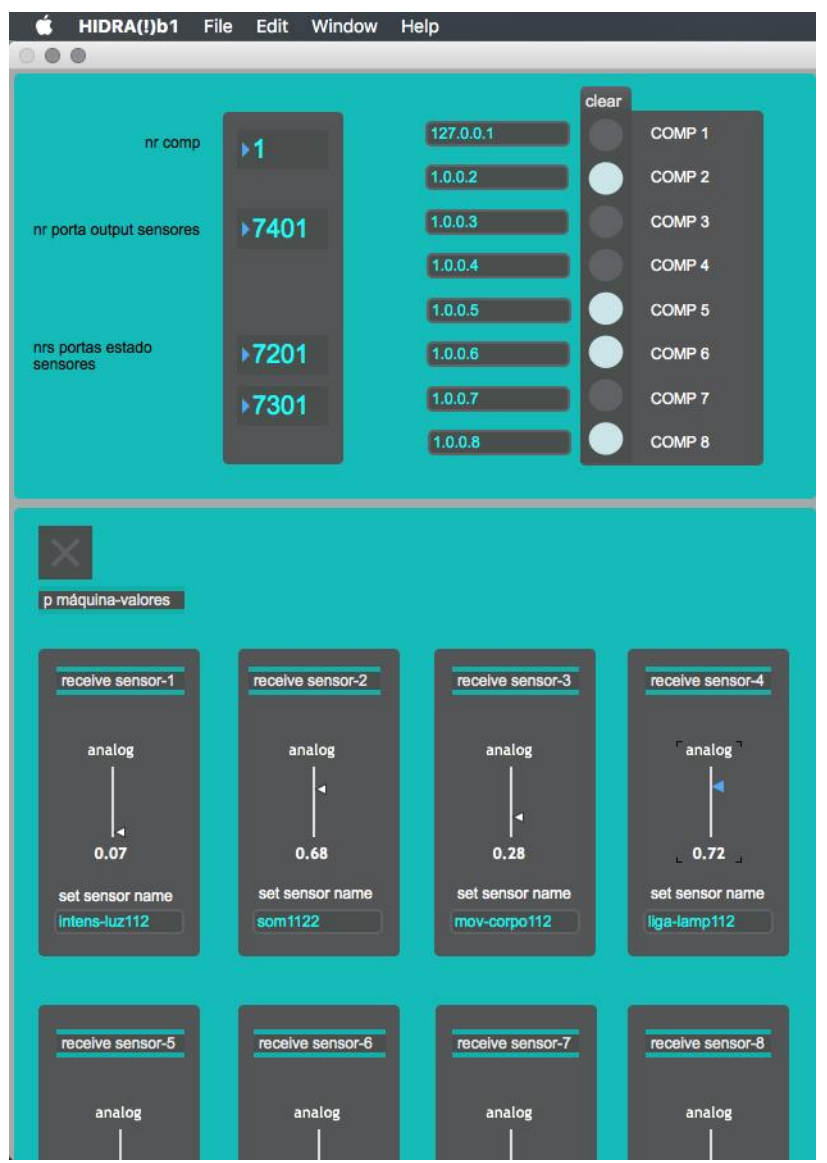

Figura 1: Interface gráfica do Sistema Hidra(!): configurando a comunicação entre terminais/computadores. Fonte: autores.

A camada de processamento do Sistema Hidra(!), como qualquer software programado na plataforma MAX7, possui dois estados principais: estado programação e estado operação. No primeiro, o usuário (ou designer de interface) pode reprogramar o software (que chamaremos de patch daqui em diante). Ele pode adicionar ou retirar funções e reorganizar o fluxo de dados. No modo operação o usuário pode operar o patch, controlando-o, alterando variáveis, alimentando-o com dados que modificam o comportamento do patch. Temos assim, dois níveis de interação possíveis: o da programação e da operação. Ambos podem ser complementares (quando se está programando um patch) ou, no caso do modo operação (quando se está controlando o patch), pode existir independentemente. É nessa camada que se encontra a possibilidade de recombinar inputs e outputs, isto é: abre-se a possibilidade de canalizar dinamicamente qualquer entrada (input) em qualquer saída (output) através de uma interface que torna visível e manipulável essas possibilidades de canalização.

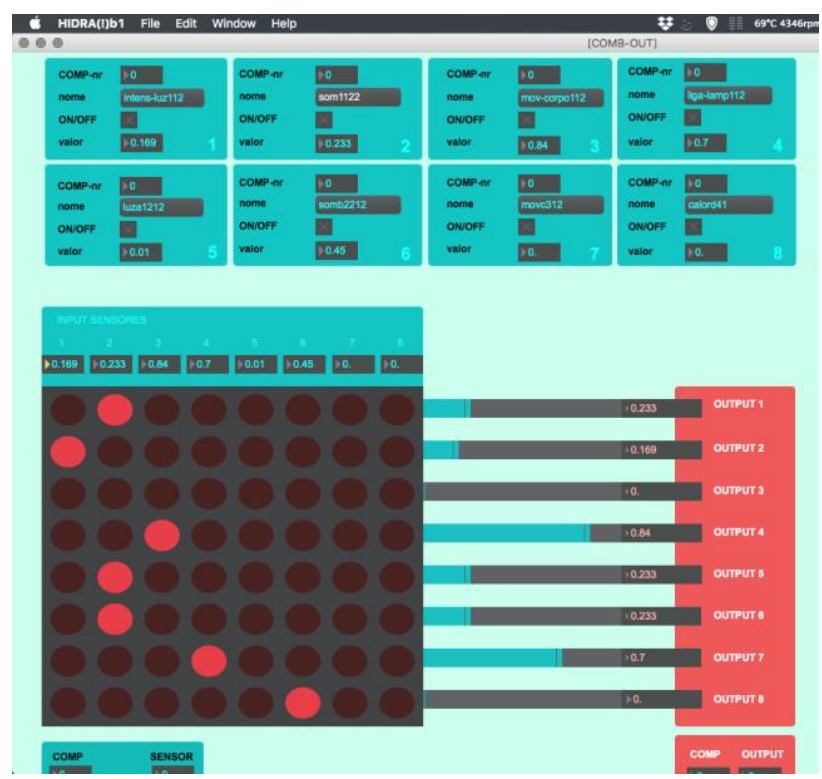

Figura 2: Interface Gráfica do Sistema Hidra(!): recombinando inputs e outputs. Fonte: autores.

\section{INPUTS - OUPUTS / INFORMAÇÃO - TRANSDUÇÃO}

Isso posto, podemos dizer que o mapeamento e a parametrização, estruturados por processos combinatórios, caracterizam a essência do Sistema Hidra(!). No entanto, cabe esclarecer que esses processos só são possíveis pois existe antes o que chamamos de descorporificação da informação, isto é, a autonomia da informação quanto a matéria ou suporte. Essa autonomia propicia a própria existência do conceito de entrada e saída de dados em processos e cômputos digitais. Isso só é possível se tomarmos o sentido de informação nos moldes de Shannon (1940). Nele, a informação não possui e não depende de um corpo, ela apenas transita por corpos e qualquer ação desses corpos nessa transmissão deve ser prevista para se compor a informação. Se não for prevista, deve ser ao menos mensurável. Essa ação indesejada, mas mensurável, é o ruído. Ainda: a informação pode se utilizar de energia luminosa ou elétrica ou mecânica para se propagar, mas a informação em si não se altera. Uma mesma informação pode trafegar por todos esses meios e sua integridade deverá ser assegurada (Papert, 1965).

Essa autonomização da informação é um conceito chave para entendermos os processos de digitalização e demais processos combinatórios digitais (que chamaremos de cômputos daqui em diante). Os inputs e outputs de um sistema digital (um computador, por exemplo) não são energia (luminosa, mecânica, elétrica) e sim informação. O input não é som, luz, sinal elétrico, mas sua transformação em informação. O input de um microfone, por exemplo, não é a onda sonora (ou um conjunto delas), mas a onda sonora tornada movimento mecânico 
que, por sua vez, é convertido em sinal elétrico. O que permanece nessas traduções é a informação. Assim, em concordância com a Teoria da Informação, a mesma informação ora é som, ora é movimento, ora é eletricidade.

Algo semelhante acontece no nível sensorial do Sistema Hidra(!): intensidades de luz, som, calor, etc., são convertidos em sinais elétricos que por sua vez são traduzidos em informação quantizável, isto é, bits de informação.

A compreensão dos processos de comunicação entre elementos do sistema é extremamente potente pois conseguimos "controlar", "dimensionar" e recombinar o que se transmite. No entanto nos deparamos com uma questão que é intransponível se abordarmos esse sistema apenas em termos de "informação": a informação nos processos digitais é da ordem da "seleção" (Lévy, 1992) isto é, a informação transmitida existia como potência, latência. Fazia parte de um conjunto de possibilidades determinadas pela sistematização algorítmica dos processos digitais que estabelecem um conjunto finito de possibilidades para que seja possível "computar". Nos sistemas digitais, portanto, não existe informação nova e sim informação selecionada a partir de conjuntos pré-determinados. Em termos técnicos: quando se traduz som em imagem via meios digitais o que está acontecendo é que se estabelece previamente um conjunto finito de bits para "receber" e digitalizar a informação sonora e posteriormente, ao converter esse conjunto de bits em imagem, estabelece-se também um conjunto finito de bits que serão reorganizados a partir de regras arbitrárias de mapeamento dos bits do som em bits da imagem. Esse entendimento, como já dissemos acima, é fundamental para a compreensão dos processos digitais. No entanto, é insuficiente para entendermos a interação entre o mundo físico (indeterminístico, acidental, onde há geração do novo) e o mundo prédeterminado dos processos computacionais. Construir a distinção entre esses dois domínios clarifica a relação, no caso desse artigo, entre IOT e RV mediada pelo humano/designer.

Para distinguirmos, portanto, processos informacionais de processos onde há possibilidade de geração do novo, mobilizaremos o conceito de transdução (Simondon, 1986).

Como vimos, a informação é uma entidade autônoma que pode assumir qualquer corpo. E nesse corpo ela permanece como informação. Ela pode até alterar esse corpo, modificando sua forma ou sua dinâmica. Mas ela permanece informação autônoma que pode ser extraída novamente na forma de outputs. A transdução, como processo transformativo, concebe a informação de uma outra maneira: a informação seria a dinâmica de padrões/estruturas interna a um domínio/corpo/meio, e informar outros domínios/corpos e meios seria a contínua ressonância desses padrões. Cada meio possui especificidades materiais, estruturas e campos virtuais latentes que determinam quais padrões são "emissíveis" e, "no outro corpo", como eles podem ressonar. No entanto, além de operar entre o que é emissível e o que é receptível, a ressonância também transforma o que emite e o que recebe.
A ideia de transdução implica em uma justaposição entre domínios/corpos e meios que se traduzem uns nos outros, sobrepondo e contaminando mutuamente seus padrões intrínsecos. Com a transdução, o meio deixa de ser caixa-preta que oferece inputs e outputs (informação pura, autonomizada, emitida e recebida via canais estabelecidos) para outras caixas-pretas para ser a contínua recriação da conexão e da separação.

Interpretando os conceitos de Simondon, Laymert G. Dos Santos pontua que "o sinal de informação não é exclusivamente o que deve ser transmitido, mas também o que deve ser recebido. Mas tal significado não pode ser encontrado nem na saída nem na chegada: a informação só existe quando o emissor e o receptor do sinal formam um sistema, ela existe entre as duas metades de um sistema díspar até então. A informação é, portanto, uma aptidão integradora, uma singularidade através da qual uma energia até então potencial se realiza." (Santos, 2003, p.85). Essa singularidade, assim, “ (...) é o germe que opera a passagem da dimensão virtual da realidade para a sua dimensão atual, possibilitando a individuação tanto de matéria quanto dos seres vivos e do objeto técnico." (Santos, 2003, p.85).

Segundo Simondon, portanto, a transdução não seria apenas um processo exclusivo dos objetos. A transdução seria um processo mais amplo: ela ocorreria entre domínios físicos, biológicos, sociais e mentais. Fundamentalmente, ela indicaria como um domínio interfere no outro. O conceito de transdução, no entanto, não pretende definir e esgotar que padrões atuam e sofrem ações. Ao apontar que padrões materiais/tecnológicos sofrem influência de padrões mentais e vice-versa, o conceito de transdução constrói a possibilidade de justaposição, mostrando que os limites desses domínios se encontram difusos, se interpenetram, e com isso provocam mudanças nos próprios domínios, recriando-os, criando novos híbridos. Nos interessa entender a relação da IOT com RV, mediados pelos Sistema Hidra(!) como uma relação de produção de novos híbridos, de limites indefinidos, parcialmente entendidos como processos de informação (quando puramente digitais) ou de transdução.

\section{MOPS}

Como estratégia didática, modelou-se o conceito de meta-objeto programável. Essa estratégia se fez necessária para uma melhor compreensão do Sistema Hidra(!): antes de explicar esse sistema para os alunos envolvidos nesse estudo, introduziu-se o conceito de MOPs. Essa abstração torna mais visíveis qualidades e potencialidades do Sistema Hidra(!) só percebidas depois de um tempo razoável de experimentação com ele. Com - conceito de MOPs ressalta-se, portanto, a desmaterialização de um objeto quanto aos seus limites físicos, com a possibilidade de recombinação entre as camadas de input e output desses objetos.

Um meta-objeto programável é um objeto organizado em três camadas fundamentais: camada sensorial (que recebe e organiza informações externas ao objeto, proveniente de uma ou várias entradas/inputs); camada processamento (que recebe informações da camada sensorial e as processa); e a camada atuante (formada 
por atuadores que externalizam informações processadas de maneira visual, sonora ou mecânica). Os meta-objetos podem ser agrupados, promovendo a comunicação entre camadas sensoriais e atuantes de diversos meta-objetos. Meta-objetos podem, assim, formar novos meta-objetos que podem, por sua vez, se recombinarem com diversos outros meta-objetos. Cada meta-objeto pode ser organizado internamente pelo que podemos chamar de módulos: unidades capazes de processar informação e se comunicar com outros módulos via entrada e saída de informação. Quando em rede, operações combinatórias entre as camadas dos MOPs podem ser realizadas. Assim, por exemplo, a camada sensorial de um MOP pode servir de input para camada processamento de um outro MOP. Este, por sua vez, pode ter sua camada atuadora fornecendo input para a camada processamento de outro MOP.

\section{METODOLOGIA}

Durante a disciplina "Arquitetura e Interatividade" do primeiro semestre de 2018, realizamos as seguintes etapas: seminários sobre IOT e RV, aulas expositivas sobre os conceitos Schinitstelle, informação e transdução, combinatória e mapeamento, workshops sobre computação física, workshops sobre utilização do Sistema Hidra(!) e apresentação do conceito de MOPs.

Além da criação do conceito de MOPs como facilitador do entendimento do Sistema Hidra(!), o conceito de MOP também ajudou na compreensão das possibilidades de hibridização entre IOT e RV. Para reforçar essa compreensão, lançou-se uma atividade que exercitasse contaminações e recombinações entre objetos interativos. Para tanto, os alunos foram orientados a escolher 3 objetos interativos produzidos na disciplina "AIA" entre os anos 2015 a 2017. A partir dessa escolha, esses objetos deveriam ser modelados em termos de MOPs, definindo suas camadas. Em seguida um novo objeto seria gerado a partir de uma possível recombinação entre essas camadas. Embora da maneira como apresentado até agora o exercício aparente ser meramente mecânico, algorítmico, na verdade em todas as etapas também se discutiu qual seria a interação desejada com essa nova configuração. A escolha, portanto, não era aleatória mas respondia à uma intenção.

Paralelamente à recombinação desses objetos, realizouse a modelagem de um espaço virtual que se comunicaria com o espaço físico e objetos interativos a partir do Sistema Hidra(!). Os elementos desse espaço virtual foram as últimas coisas a serem definidas nessa atividade. Foi sempre um desafio para os alunos proporem como deveria ser esse espaço, que objetos deveriam existir ali para dialogar com os objetos interativos físicos. Essa indefinição não foi considerada um problema. Pelo contrário, demonstrava que os alunos estavam cientes da complexidade dessa relação.

Essa dificuldade começou a esvanecer quando foi proposta uma nova rodada de hibridização, agora entre os objetos criados na própria disciplina. Essa hibridização devia considerar também a conexão desses objetos com o Sistema Hidra(!). Foi nesse momento que ficou evidente para os alunos o entendimento da diluição dos limites físicos de seus objetos ao entender que os limites de influência do seu objeto (e daquilo que o influencia) não se restringia às suas imediações. Assim, completou-se a compreensão do conceito de MOPs: em um primeiro momento compreendeu-se o potencial combinatório para a geração de novos objetos e, finalmente, a possibilidade de expandir esse novo objeto para além da sua materialidade e seus limites físicos.

Nessa fase, quando entendeu-se a dimensão sistêmica desse conjunto de objetos, novas propostas para o ambiente virtual começaram a surgir. Em sua maioria, essas propostas exploravam a ideia de que o ambiente virtual não deveria ser meramente um espelho dos objetos físicos. Devia-se explorar nesse ambiente virtual algo que complementasse o que era visto no ambiente físico/objetos.

\section{RESULTADOS}

Como vimos, durante o processo de criação dos objetos interativos, rodadas de recombinação entre os novos objetos foram realizadas. Depois de várias iterações, os objetos passaram a se desintegrar e se tornar instalações interativas (deixaram de ser objetos manipuláveis e se tornaram instalações visitáveis). Além disso, um dos objetos se transformou em uma espécie de corporificação da possibilidade de recombinação do Sistema Hidra(!): "objeto-cabos" que quando conectados à duas instalações, indicavam para o Sistema Hidra(!) que ele deveria mapear os inputs de uma instalação na outra. No total foram produzidas 4 novas instalações, além dos objeto-cabos.

Paralelamente à construção desses objetos/instalações físicas tivemos também a modelagem de um ambiente virtual. Esse ambiente era acessado via óculos de RV HTC Valve. A configuração final desse ambiente virtual era composta por 4 cubos coloridos de $30 \times 30 \mathrm{~cm}$ que se comportavam como interfaces virtuais para as instalações interativas. Esses cubos podiam ser encaixados entre si. Ao promover o encaixe, os inputs de uma instalação eram mapeados em outra instalação. Esses cubos estavam situados em uma réplica virtual da sala onde as instalações estavam situadas. Ao encaixar dois cubos, além de remapear os inputs e outputs, a geometria da região da sala era distorcida. Essa distorção, por sua vez, era parametrizada pela variação dos inputs e outputs.

A esse conjunto de MOPs físicos e virtuais demos o nome de IOT/RV/MOP-1. O ambiente virtual transformou-se, assim, em uma interface para a recombinação dos inputs e outputs das instalações. De certa forma, mostrou-se como sendo uma instância tridimensional do Sistema Hidra(!).

Essa versão 3D do Sistema Hidra(!) não anulava a manipulação direta desse sistema. Ainda foi possível alterar as combinações via Sistema Hidra(!) a partir de sua interface gráfica, acessível em cada instalação pois cada uma delas estava conectada a um computador. Nesse computador o usuário poderia estabelecer de onde viria o input para a sua instalação e para onde ele disponibilizaria os outputs desta. Ao acessar a interface gráfica do Sistema Hidra(!) havia ainda a possibilidade do usuário abrir a camada de programação desse sistema, podendo reprogramar o próprio comportamento da instalação e não apenas seus inputs e outputs.
5 
Entendemos que foge do escopo desse artigo a descrição detalhada desses objetos/instalações. Como resultado enfatizamos, portanto, a descrição da construção do sistema como um todo mesmo por que os objetos/instalações não foram "concluídos": até o final da disciplina esses objetos/instalações foram continuamente modificados (sua posição no espaço, seus limites físicos e seus componentes). Essa falta de conclusão não foi vista como um problema. Pelo contrário: foi incentivada a criação dos objetos/instalação enfatizando-se o contínuo redesenho do sistema e da relação entre seus elementos em detrimento da cristalização de um produto final.

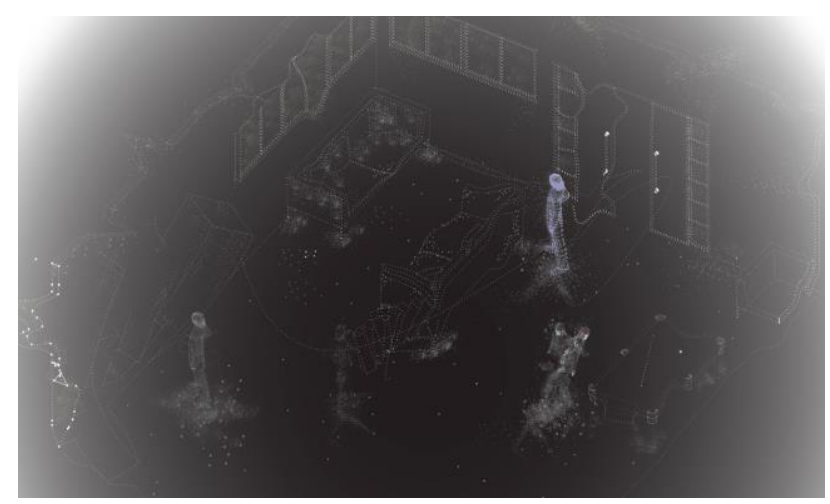

Figura 3: Ambiente Virtual sendo distorcido pelo fluxo de inputs e outputs. Fonte: autores.

\section{CONCLUSÃO}

No desenho e sucessivos redesenhos dos objetos/instalações conectados ao Sistema Hidra(!) o que está em jogo é a fricção entre o mundo determinístico da programação desse sistema e a possibilidade desse sistema (ao organizar e tornar tangível combinações possíveis entre informações captadas e processadas) de proporcionar apropriações novas, não previstas. Nesse sentido, em essência, o Sistema Hidra(!) é um mero recurso determinístico que facilita a aparição de possibilidades latentes, pois fornece ao usuário a facilidade de transformar eventos captados de um ambiente físico em informação manipulável e recombinável. Assim, mais importante que a atual configuração desse sistema são os princípios que norteiam seu desenho, tornando-o, a um só tempo, manifestação tangível de um conjunto de conceitos (Shinitstelle, informação, transdução) e ferramenta que possibilita a exploração desse conjunto ao explorar interações imprevisíveis. Dessa forma, o Sistema Hidra(!), em conjunto com o usuário/interator/programador, funciona como catalizador de possibilidades latentes que fazem sentido, que respondem a um problema ou ajudam a problematiza-lo. Essa camada combinatória introduzida pelo Sistema Hidra(!) pode, portanto, potencializar a composição entre Internet das Coisas e Realidade Virtual ao disponibilizar a recombinação dinâmica entre seus elementos. Inputs provenientes de sensores podem ser endereçados a qualquer processo de computação vinculado ao Sistema Hidra(!).

Com o Sistema Hidra(!) e com o conceito de MOP conseguimos enxergar um objeto interativo para além dos seus limites físicos, entendendo que cada MOP está potencialmente distribuído em rede, sendo que suas camadas mais externas podem ser qualquer camada externa de qualquer MOP da rede. Com isso em vista, pudemos visualizar e experimentar contínuas atualizações das relações de troca de inputs e outputs dos componentes da rede. Esse entendimento topológico da rede para além de sua geografia (distribuição física de seus elementos) provocou uma contaminação entre as camadas mais externas dos objetos. Em um segundo momento, entendeu-se que o processo era de hibridização contínua entre aspectos digitais e analógicos, entre processos de transdução e informação. A tensão entre esses campos e domínios apresentou-se, assim, como motor criativo, como geradora de novos híbridos.

Finalmente, quando promovemos a convergência entre os conceitos aqui expostos e os experimentos de redesenho de interfaces/objetos/instalações estamos alinhados com a visão construtivista da tecnologia, de Andrew Feenberg (1991), que se opõe à visão determinista e instrumental da tecnologia. Nessa visão, a tecnologia deve ser aberta, isto é, ser projetada e desenhada para poder receber alterações. O design de interfaces dessa natureza passa pela coordenação de seus níveis programáveis e prédeterminados (ainda que este possua a possibilidade de se auto-organizar, de se adaptar automaticamente, até mesmo "aprendendo" com o comportamento do usuário) com a indeterminação de eventos futuros nascidos da tensão entre o pré-estabelecido e o acidental, imponderável e imprevisível, enfim, dimensões virtualizantes e criativas do real. Com essa abordagem, empoderamos o usuário ao transforma-lo de um mero operador para alguém que participa do redesenho contínuo das interfaces por ele acessadas ou criadas.

\section{REFERÊNCIAS}

FEENBERG, A. (1991). Critical Theory of Technology. New York: Oxford University Press.

LÉVY, P. (1992). O Que é Virtual? São Paulo: editora 34.

PAPERT, S. (1965). Introduction to Embodiments of Mind by Warren S. McCulloch. Cambridge: M.I.T. Press, p.23.

PASK, G. (1975). Conversation Theory. London: Hutchinson.

SANTOS, A.P. B. Por uma arquitetura virtual: uma crítica das tecnologias digitais'. Revista AU, Arquitetura e Urbanismo, São Paulo, № 131, 2005, pp. 57-60.

SHANNON, C. E. A Symbolic Analysis of Relay and Switching Circuits. Cambridge: MIT Press, 1940.

SIMONDON, G. (1989) Du mode d'existence des objets techniques. Paris: Aubier.

ZIELINSKI, S. (1997). Interfacing Realities. Rotterdam: Uitgeverij DeBaile and Idea Books. 